\title{
Pengontrolan Kecepatan Mobile Robot Line Follower Dengan Sistem Kendali PID
}

\author{
Hendri Miftahul ${ }^{1}$, Firdaus $^{2}$, Derisma $^{3}$ \\ ${ }^{1,3}$ Jurusan Sistem Komputer Universitas Andalas \\ Jl. Universitas Andalas, Limau Manis, Pauh, Limau Manis, Pauh, Kota Padang, Sumatera Barat 25163 \\ ${ }^{2}$ Teknik Elektro Politeknik Negeri Padang \\ Kampus Limau Manis, Limau Manis, Pauh, Kota Padang, Sumatera Barat 25163 \\ derisma@fti.unand.ac.id
}

\begin{abstract}
Abstrak - Perkembangan teknologi robotika telah mampu menciptakan robot cerdas yang memiliki keistimewaan-keistimewaan khusus, salah satunya yaitu mobile robot line follower. Mobile robot line follower merupakan suatu jenis robot beroda yang memiliki sensor untuk mendeteksi suatu garis dengan pola tertentu yang bergerak mengikuti garis tersebut. Untuk memberikan perubahan pergerakkan mobile robot line follower menjadi lebih halus tanpa menimbulkan pergerakan yang kaku maka pengaturan kecepatan mobile robot line follower dapat dilakukan dengan menggunakan sistem kendali PID (Proportional Integral Derivative). Sistem kendali PID digunakan untuk mengkoreksi error dari pengukuran variabel input (sensor) agar output sistem sesuai dengan nilai set point untuk menghasilkan error yang sekecil mungkin. Berdasarkan hasil percobaan yang dilakukan, didapatkan nilai parameter kontrol PID yang terbaik dengan nilai $K p=9, K d=3$ dan $K i=1$, dimana nilai tersebut mampu merespon posisi mobile robot line follower agar selalu mendekati nilai set point dan memiliki waktu yang tercepat mencapai finis dengan waktu 6930 ms.
\end{abstract}

Kata kunci: mobile robot line follower, sensor, PID (Proportional Integral Derivative)

\section{Pendahuluan}

Robotika merupakan suatu bidang kajian ilmu yang terus berkembang dengan sangat pesat. Saat ini perkembangan teknologi robotika telah mampu menciptakan robot cerdas yang memiliki keistimewaan-keistimewaan khusus. Mobile robot [1] merupakan sebuah robot yang bergerak, dimana sistem robot tersebut mampu memindahkan dirinya sendiri dari posisi A ke posisi B, dimana kedua posisi tersebut berada pada jarak tertentu (keseluruhan badan robot berpindah tempat), bisa dikatakan bahwa robot tersebut bergerak dinamis. Salah satu jenis mobile robot yang memiliki keistimewaan dan sering dikembangkan yaitu mobile robot line follower (pengikut garis).

Robot jenis line follower bergerak menggunakan aktuator berupa motor DC. Biasanya jenis penggerak robot line follower memiliki 2 buah motor DC yang dipasang di sebelah kiri dan kanan robot. Untuk dapat menggerakkan robot maka masing-masing motor DC diatur kecepatannya melalui sebuah rangkaian driver motor.

Pengaturan kecepatan masing-masing motor DC sangat menentukan tingkat kestabilan perubahan pergerakan mobile robot line follower dari kondisi berbelok ke kondisi bergerak lurus maupun sebaliknya.

Pengaturan kecepatan motor DC ini dapat dilakukan dengan menggunakan sistem kendali PID (Proportional Integral Derivative). Pengendali PID[2] adalah suatu sistem pengendali yang merupakan gabungan antara pengendali Proportional, Integral dan Derivative. Sistem kendali PID digunakan untuk mengkoreksi error dari pengukuran variabel input (sensor) agar output sistem sesuai dengan nilai set point untuk menghasilkan error yang sekecil mungkin. Berdasarkan latar belakang diatas, maka penulis akan merancang merancang dan membuat mobile robot line follower yang dikontrol dengan pengendali PID untuk mengatur kecepatan motor DC berbasis

TELKA, Vol.2, No.2, November 2016, pp. 150 159

ISSN (e): 2540-9123

ISSN (p): 2502-1982 
Mikrokontroler ATMega 8535 sehingga pergerakkan robot line follower menjadi lebih halus dan tidak kaku.

\section{Metode Penelitian}

\subsection{Perancangan Sistem}

Sebelum melakukan perancangan sistem, terlebih dahulu dibuat diagram blok sebagai langkah awal pembuatan sistem.

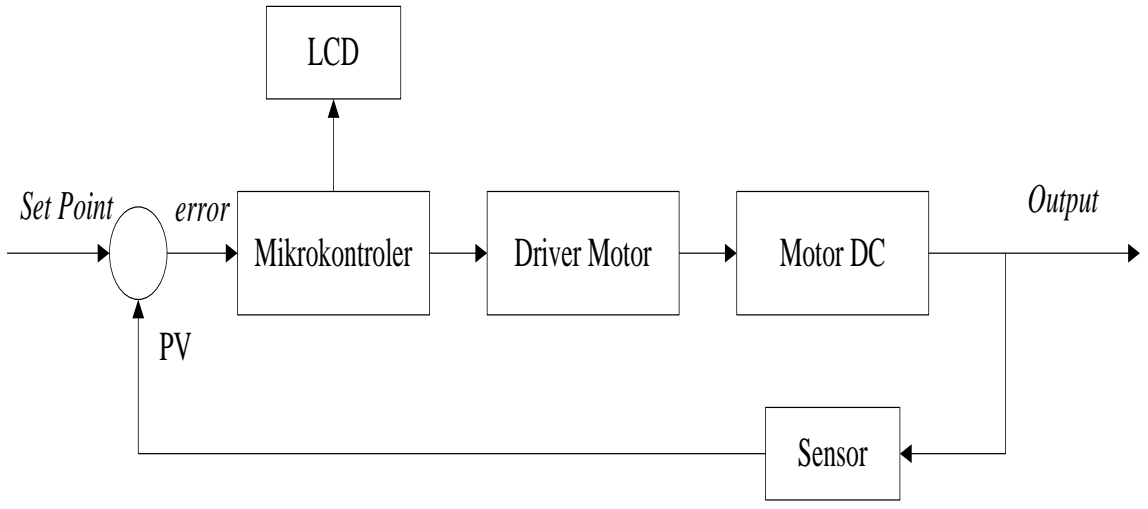

Gambar 1. Diagram Blok Sistem

\subsubsection{Mikrokontroler ATMega 8535}

Mikrokontroler[11] merupakan sebuah sistem mikroprosesor di mana di dalamnya sudah terdapat Central Processing Unit (CPU), Read Only Memory (ROM), Random Access Memory (RAM) , Input/Output (I/O), clock dan perlatan internal lainnya yang sudah terhubung dan terorganisasi dengan baik dan dikemas dalam satu chip yang siap pakai.

\subsubsection{Driver Motor L298}

L298 adalah IC yang dapat digunakan sebagai driver motor DC. IC ini menggunakan prinsip kerja H-Bridge. Tiap H-Bridge dikontrol menggunakan level tegangan TTL yang berasal dari output mikrokontroler.

\subsubsection{Motor DC Magnet Permanen}

Motor DC (direct current) merupakan jenis motor yang menggunakan tegangan searah sebagai sumber tenaganya. Dengan memberikan beda tegangan pada kedua terminal tersebut, motor akan berputar pada satu arah, dan bila polaritas dari tegangan tersebut dibalik maka arah putaran motor akan terbalik pula. Polaritas dari tegangan yang diberikan pada dua terminal menentukan arah putaran motor sedangkan besar dari beda tegangan pada kedua terminal menentukan kecepatan motor.

\subsubsection{Liquid Crystal Display (LCD)}

Liquid Crystal Display (LCD)[12] adalah suatu display dari bahan cairan Kristal yang pengoperasiannya menganut sistem dot matrix.

\subsubsection{Light Emitting Diode (LED)}

LED[5] adalah perangkat semikonduktor yang memancarkan cahaya berspektrum sempit ketika dialirkan listrik dengan arah maju. Efek ini merupakan bentuk dari electroluminescence. Warna dari cahaya yang dipancarkan tergantung pada komposisi dan keadaan semikonduktor yang digunakan, dan dapat berupa infrared, cahaya tampak atau mendekati ultraviolet. 


\subsubsection{Photodioda}

Photodioda[6] merupakan salah satu jenis sensor optik yang digunakan dalam rangkaian elektronika untuk mengukur intensitas cahaya. Photodioda disusun menggunakan 2 buah pin. Bagian yang panjang berkutub positif (+) dan bagian yang pendek berkutub negatif (-). Keluaran photodiada adalah arus listrik yang berubah sesuai intensitas cahaya yang masuk. Semakin terang atau semakin banyak intensitas cahaya yang masuk, keluaran photodioda semakin kecil.

\subsection{Perancangan Hardware}

\subsubsection{Rangkaian Sistem Minimum ATmega 8535}

Rangkaian sistem minimum dalam penelitian ini tergambar pada gambar berikut.

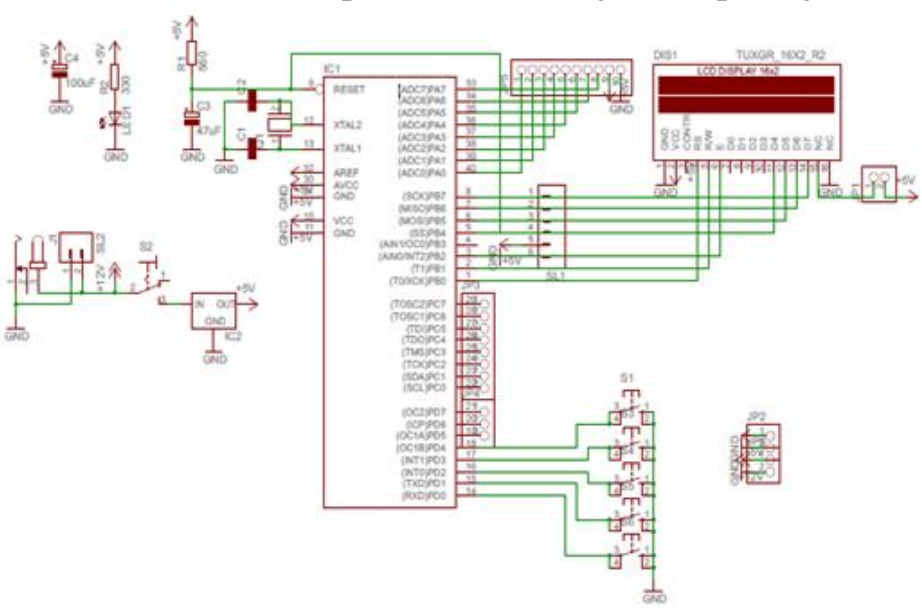

\subsubsection{Rangkaian Sensor}

Gambar 2. Skema Rangkaian Sistem Minimum

Rangkaian sensor dalam penelitian terlihat pada gambar 3.
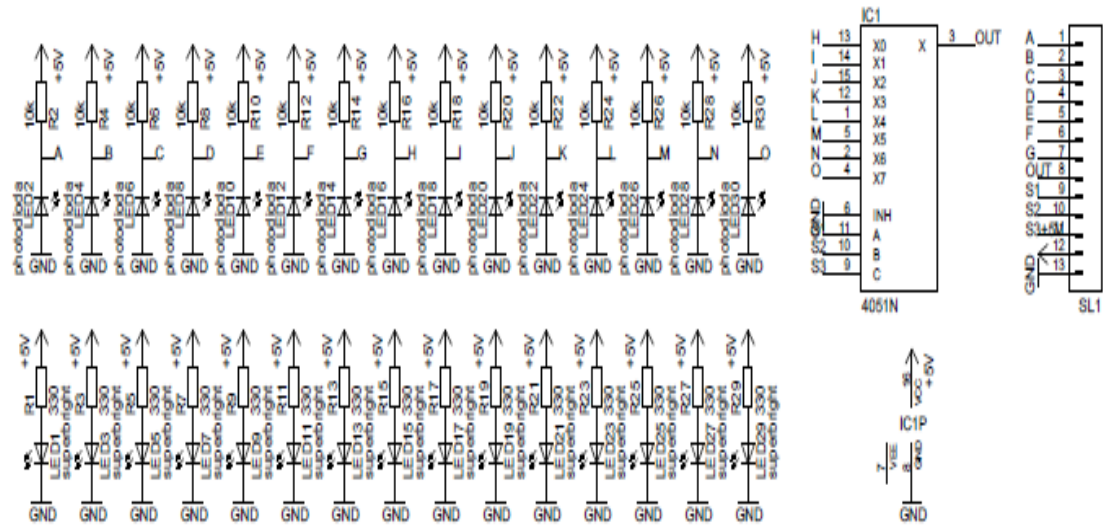

Gambar 3. Rangkaian Sensor

\subsubsection{Rangkaian Driver Motor}

ISSN (e): 2540-9123

ISSN (p): 2502-1982 
Rangkaian driver motor dalam penelitian terlihat pada gambar 4.

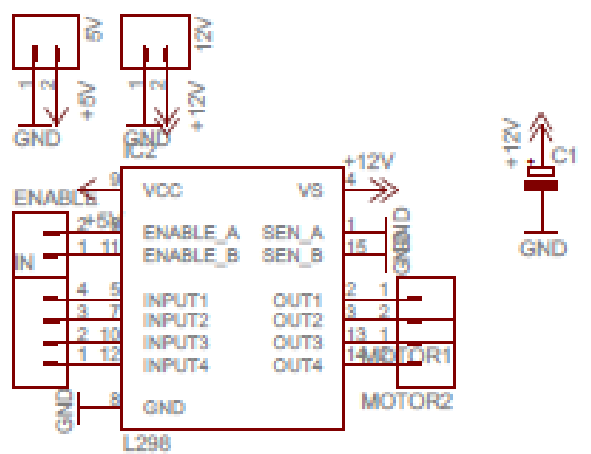

Gambar 4. Rangkaian Driver Motor

\subsection{Perancangan Mekanik}

Hasil perancangan mekanik robot line follower dapat dilihat pada gambar 5.

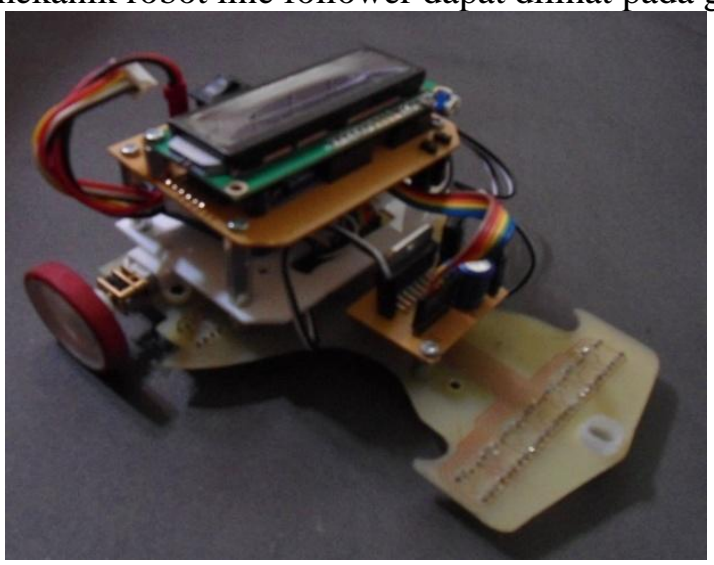

Gambar 5. Hasil Perancangan Mekanik Robot Line Follower

\subsection{Perancangan Kendali PID}

Berdasarkan ketiga parameter kontrol maka keseluruhan nilai PID yang didapatkan adalah dengan menjumlahkan seperti persamaan 1 .

$$
P I D=P+I+D
$$

\subsubsection{Perancangan Software Robot Line Follower dengan Kendali PID}


Flowchart perancangan software Robot Line follower terlihat pada gambar 6 dan gambar 7 berikut.

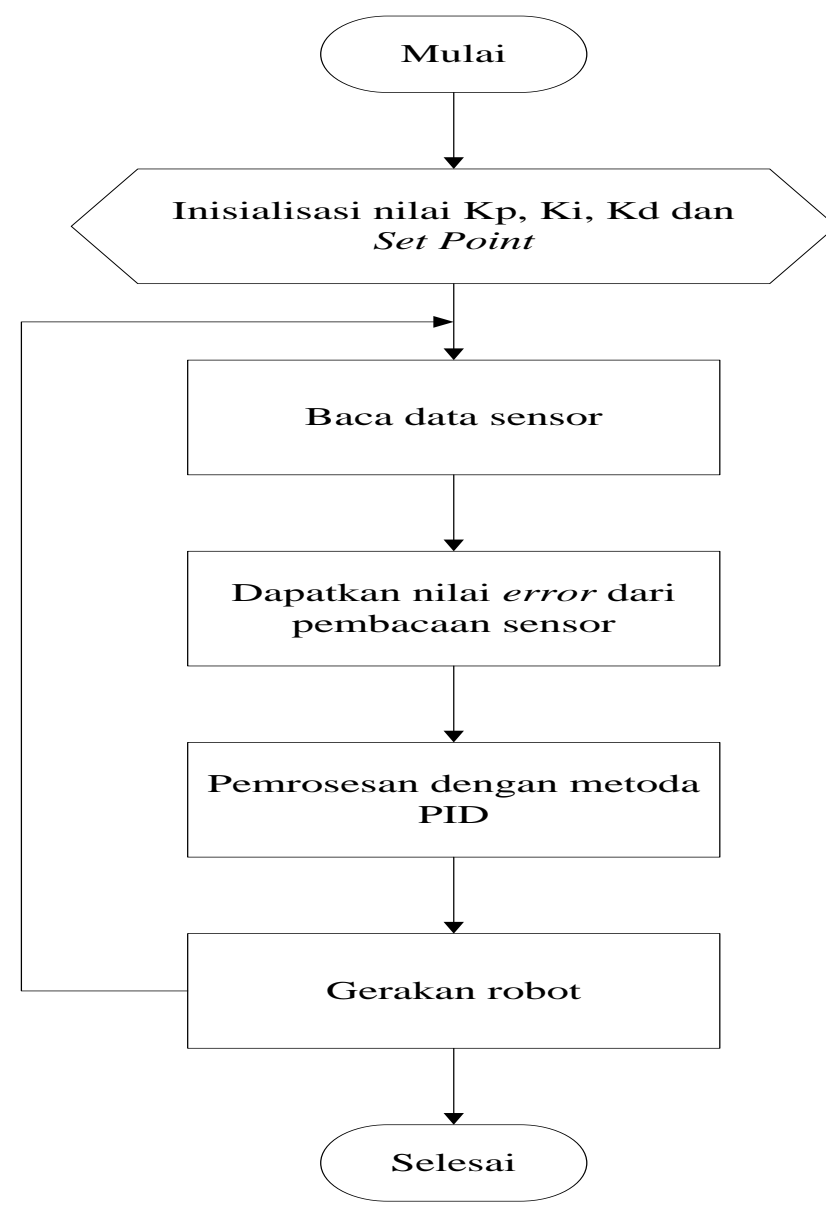

Gambar 6. Flowchart Utama Robot Line Follower 


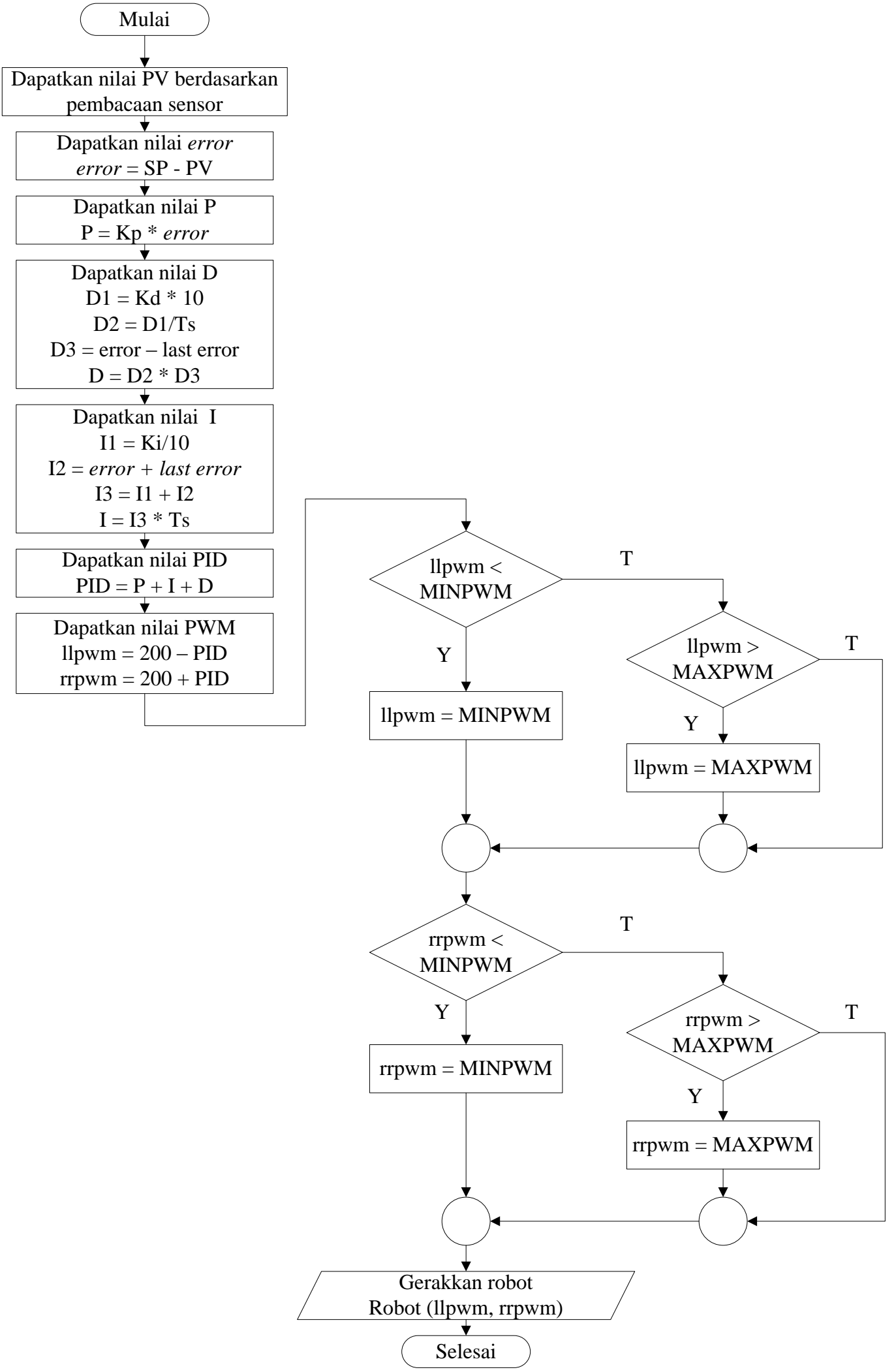

Gambar 7. Flowchart Program Kendali PID Robot Line Follower 


\section{Hasil dan Analisa}

\subsection{Pengujian Alat}

\subsubsection{Pengujian Sensor Garis}

Tabel 1. Hasil Pengukuran Tegangan Photodioda

\begin{tabular}{|l|l|l|l|}
\hline & Tegangan Input & $\begin{array}{c}\text { Tegangan di permukaan } \\
\text { putih }\end{array}$ & $\begin{array}{l}\text { Tegangan di garis } \\
\text { hitam }\end{array}$ \\
\hline LED & $2,8 \mathrm{~V}$ & - & - \\
\hline Sensor 1 & - & $0,2 \mathrm{~V}$ & $4,2 \mathrm{~V}$ \\
\hline Sensor 2 & - & $0,15 \mathrm{~V}$ & $3,4 \mathrm{~V}$ \\
\hline Sensor 3 & - & $0,15 \mathrm{~V}$ & $3,7 \mathrm{~V}$ \\
\hline Sensor 4 & - & $0,15 \mathrm{~V}$ & $3,6 \mathrm{~V}$ \\
\hline Sensor 5 & - & $0,15 \mathrm{~V}$ & $3,7 \mathrm{~V}$ \\
\hline Sensor 6 & - & $0,15 \mathrm{~V}$ & $3,9 \mathrm{~V}$ \\
\hline Sensor 7 & - & $0,2 \mathrm{~V}$ & $4,2 \mathrm{~V}$ \\
\hline
\end{tabular}

Nilai tegangan di permukaan putih dan permukaan hitam pada masing-masing sensor didapatkan dari hasil pengukuran menggunakan multimeter. Berdasarkan tabel 1 dapat disimpulkan bahwa ketika sensor berada dipermukaan putih nilai tegangannya lebih rendah dari pada ketika sensor berada di garis hitam.

\subsubsection{Pengujian PWM (Pulse Width Modulation)}

Pulse Width Modulation (PWM)[9] secara umum adalah sebuah cara memanipulasi lebar sinyal yang dinyatakan dengan pulsa dalam suatu perioda, untuk mendapatkan tegangan rata-rata yang berbeda.

Tabel 2. Nilai LPWM dan RPWM Motor

\begin{tabular}{|c|c|c|}
\hline PV & LPWM & RPWM \\
\hline $\mathrm{PV}=8$ & 255 & 112 \\
\hline $\mathrm{PV}=7$ & 255 & 123 \\
\hline $\mathrm{PV}=6$ & 255 & 134 \\
\hline $\mathrm{PV}=5$ & 255 & 145 \\
\hline $\mathrm{PV}=4$ & 244 & 156 \\
\hline $\mathrm{PV}=3$ & 233 & 167 \\
\hline $\mathrm{PV}=2$ & 222 & 178 \\
\hline $\mathrm{PV}=1$ & 211 & 189 \\
\hline $\mathrm{PV}=0$ & 255 & 255 \\
\hline $\mathrm{PV}=-1$ & 189 & 211 \\
\hline $\mathrm{PV}=-2$ & 178 & 222 \\
\hline $\mathrm{PV}=-3$ & 167 & 233 \\
\hline $\mathrm{PV}=-4$ & 156 & 244 \\
\hline $\mathrm{PV}=-5$ & 145 & 255 \\
\hline $\mathrm{PV}=-6$ & 134 & 255 \\
\hline $\mathrm{PV}=-7$ & 123 & 255 \\
\hline $\mathrm{PV}=-8$ & 112 & 255 \\
\hline
\end{tabular}


Dari tabel 2 didapatkan nilai PWM masing-masing motor pada tiap posisi pembacaan sensor. Nilai PWM tersebut didapatkan dari pembacaan nilai PWM yang keluar dari LCD. Dapat diperhatikan bahwa saat PV bernilai 0 nilai PWM motor kanan dan motor kiri adalah sama yaitu bernilai 255. Pada saat nilai PV tidak sama dengan 0 maka nilai PWM motor kanan dan motor kiri memiliki nilai PWM yang berbeda sesuai dengan besarnya perubahan nilai PV. Semakin besar nilai perubahan PV maka semakin berkurang nilai PWM salah satu motor.

\subsection{Pengujian PID}

\subsubsection{Pengujian pada Garis Lurus}

Data hasil pengujian akan disajikan dalam bentuk grafik pengujian PID. Grafik pengujian PID dapat dilihat pada gambar 8 .

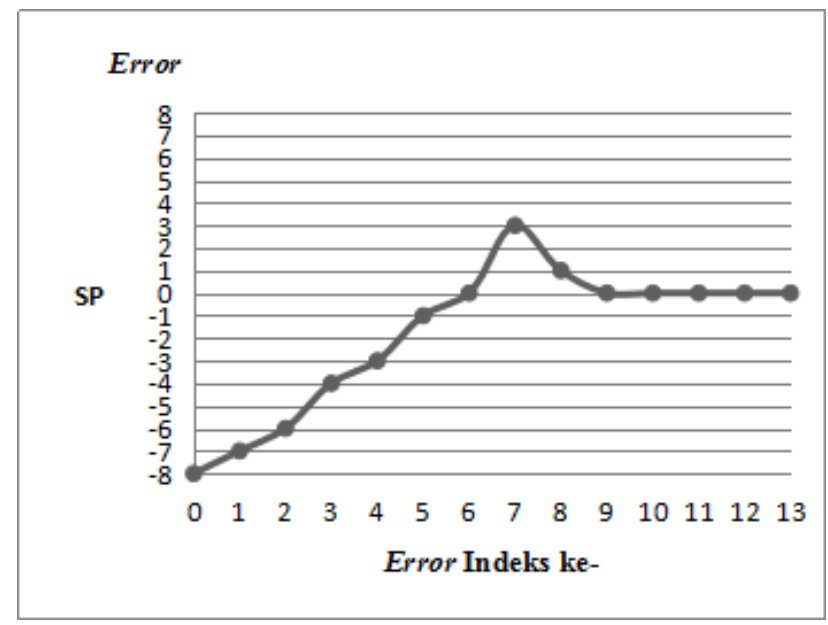

Gambar 8. Grafik Pengujian PID

Gambar 4. terlihat bahwa dengan menggunakan kendali PID pada saat robot diletakkan pada posisi error $=-8$, robot mampu bergerak dengan baik dan selalu mendekati nilai set point, dimana nilai set point dari robot ini yaitu 0 .

\subsubsection{Pengujian pada Lintasan}

Tabel 3. Pengujian Waktu pada Lintasan

\begin{tabular}{|c|c|c|c|c|}
\hline \multirow{2}{*}{ NO } & \multicolumn{3}{|c|}{ PID } & \multirow{2}{*}{ T (ms) } \\
\cline { 2 - 4 } & P & D & I & \\
\hline 1 & 9 & 0 & 0 & 6960 \\
\hline 2 & 9 & 1 & 0 & 7150 \\
\hline 3 & 9 & 2 & 0 & 7060 \\
\hline 4 & 9 & 3 & 0 & 6970 \\
\hline 5 & 9 & 4 & 0 & 6980 \\
\hline 6 & 9 & 5 & 0 & 6980 \\
\hline 7 & 9 & 3 & 1 & 6930 \\
\hline 8 & 9 & 3 & 2 & 6950 \\
\hline 9 & 9 & 3 & 3 & 7060 \\
\hline 10 & 9 & 3 & 4 & 7330 \\
\hline
\end{tabular}


Berdasarkan tabel 3 dengan memberikan nilai parameter $\mathrm{Kp}$, Ki dan $\mathrm{Kd}$ yang berbeda dapat kita simpulkan bahwa dengan pemberian nilai parameter $\mathrm{Kp}=9, \mathrm{Kd}=3$ dan $\mathrm{Ki}=1$ didapatkan waktu tercepat dalam mencapai garis finis yaitu dengan waktu $6930 \mathrm{~ms}$.

\section{Penutup}

\subsection{Kesimpulam}

Berdasarkan pengujian dan analisa yang telah dilakukan, maka dapat disimpulkan beberapa hal sebagai berikut :

1. Pemberian nilai variabel $\mathrm{Kp}, \mathrm{Kd}$ dan $\mathrm{Ki}$ yang dilakukan dengan metoda Trial and error didapatkan nilai parameter kontrol PID yang terbaik dengan nilai $\mathrm{Kp}=9, \mathrm{Kd}=3$ dan $\mathrm{Ki}=1$, dimana nilai tersebut mampu merespon posisi robot line follower agar selalu mendekati nilai set point dan memiliki waktu yang tercepat mencapai finis dengan waktu $6930 \mathrm{~ms}$.

2. Pengujian robot line follower pada garis lurus sepanjang \pm 1 meter didapatkan perubahan nilai error yang memiliki rentang nilai dari error bernilai -8 sampai dengan error bernilai 3 . Adapun kondisi ideal dari robot line follower yaitu terletak pada posisi error $=0$ atau pada nilai $\mathrm{PV}=0$.

3. Nilai maksimal PWM pada robot line follower ini yaitu bernilai 255 dan nilai minimal PWM dari robot line follower yaitu bernilai -255 .

4. Kendali PID mampu mengkoreksi nilai error, dimana nilai error tersebut diolah dengan perhitungan PID untuk dijadikan sinyal kendali yang diteruskan ke motor sehingga kecepatan motor dapat berubah-ubah sesuai dengan bobot pembacaan sensor sehingga menimbulkan pergerakkan robot line follower menjadi lebih halus tanpa menimbulkan pergerakan yang kaku

\subsection{Saran-saran}

Adapun saran yang dapat diberikan untuk membuat sistem dapat berjalan menjadi lebih sempurna sehingga sistem tersebut dapat memiliki fungsi yang lebih baik adalah sebagai berikut

1. Menentukan nilai parameter kontrol proportional, integral dan derivative dapat dilakukan dengan metoda osilasi lain seperti Ziegler-Nichols karena metoda tersebut telah menggunakan rumus-rumus yang sederhana yang dapat mempersingkat waktu dalam pencarian nilai parameter PID.

2. Untuk posisi sensor, antara sensor yang satu dengan sensor yang lainnya sebaiknya diberi pembatas untuk mengurangi intensitas cahaya yang datang dari luar.

\section{Daftar Pustaka}

[1] Pramana, Agus, dkk. 2007. Perancangan Prototipe Kontrol Mobile Robot Pemindah Benda. Universitas Bina Nusantara.

[2] Laksana, Andra. Balancing Robot Beroda Dua Mengggunakan Metode Kendali Proporsional Integral. Universitas Diponegoro.

[3] Raditya, Bregas. 2011. Pengendali Motor Servo DC Menggunakan PI untuk Diimplementasikan pada Mesin CNC. Universitas Bina Nusantara.

[4] Harry, dkk. 2006. Kontrol Posisi pada Motor DC dengan FPGA. Universitas Bina Nusantara.

[5] Antoni, dkk. 2007. Perancangan Modul dengan Pengaturan Grayscale pada Dot Matrix (Prototype). Universitas Bina Nusantara. 
[6] Fajar, Khairul. 2011. Analisis Efisiensi Sensor Cahaya (LDR, Photodioda dan Phototransistor) pada Rancang Robot Pemadam Api. Universitas Islam Negeri Maulana Malik Ibrahim Malang.

[7] Pitowarno, Endra. 2006. Robotika Desain, Kontrol dan Kecerdasan Buatan. Yogyakarta: Andi Yogyakarta.

[8] Firdaus. 2010. Rancang Bangun Sistem Kendali Kecepatan Kursi Roda Listrik Berbasiskan Disturbance Observer. Institut Teknologi Sepuluh November Surabaya.

[9] Prayogo, Rudito. 2012. Pengaturan PWM (Pulse Width Modulation) dengan PLC. Universitas Brawijaya Malang.

[10] Novendy, dkk. 2006. Pengimplementasian Ultrasonic terhadap Mobile Robot sebagai Penjejak (Object Follower). Universitas Bina Nusantara.

[11] Syahrul. 2012. Mikrokontroler AVR ATmega 8535. Bandung: Informatika Bandung.

[12] Budy. 2011. Sistem Pengamanan Kunci Sepeda Motor Menggunakan Radio Frequency Identification (RFID). STMIK AMIKOM Yogyakarta. 